\title{
Detectability for GPS, EDM and tiltmeters of the Hot Springs Research Institute in the western Kanagawa prefecture, Japan
}

\author{
Toshikazu Tanada \\ Hot Springs Research Institute of Kanagawa Prefecture, Iriuda 586, Odawara, Kanagawa 250-0031, Japan
}

(Received December 31, 1999; Revised August 15, 2000; Accepted August 15, 2000)

\begin{abstract}
To better understanding the observation data, we attempt to assess the detectability for the crustal deformation observation network of the Hot Springs Research Institute of Kanagawa prefecture (HSRI). The HSRI has carried out continuous monitoring of crustal deformation with GPS, EDM, borehole tiltmeters, groundwater leveling since 1989. Our observation purpose is to detect the pre-, co- and post-seismic deformations of the hypothetical M7 class earthquake designated as the "Western Kanagawa Prefecture Earthquake (WKE)". In order to estimate the detectability, we apply a simple calculation method, that is comparing between co-seismic deformation (displacement and tilt) and the accuracy of observation instruments. Co-seismic deformation is calculated using the Okada's method, which is a formulation of the expected crustal deformation due to seismic faulting as a function of an earthquake magnitude and a hypocentral distance without assuming focal mechanism. It is indicated that the highest detectability area is located in the center of our HSRI observation network. Comparing detectability contour maps for several kinds of networks, we can find that the detectability of the co-seismic deformation by the tiltmeter network is higher than those by the GPS and EDM networks in the case of the M5 class earthquake with a focal depth of $10 \mathrm{~km}$, and that the detectability by the GPS network is almost equal to that by the EDM network in the case of the M6 class earthquake with a focal depth of shallower than $15 \mathrm{~km}$. For M4 class earthquakes, it is difficult for the GPS, EDM and tiltmeter networks to detect co-seismic deformation. The present result shows advantageous characteristics of the HSRI geodetic network and an important constraint on investigating the pre-, co- and post-seismic deformation of the WKE. To monitor the pre-, co- and post-seismic deformation of the WKE, it is necessary to combine these observations in the most effective way.
\end{abstract}

\section{Introduction}

The study area is located in the northeastern part of the Izu Peninsula and has repeatedly experienced large earthquakes with magnitudes of 7 to 8 . This can be attributed to the facts that the Izu Peninsula is colliding with the Honshu Arc although the Philippine Sea plate is subducting from the Sagami and Suruga-Nankai troughs. According to the historical data, large earthquakes have occurred in a cycle of about 70 years in the region (Ishibashi, 1988). Since the previous devastating earthquake was the Kanto earthquake of 1923, which caused the largest damage to Odawara and Hakone, it has been pointed out that the next disastrous earthquake can be expected in the near future. The Kanagawa prefectural government named this hypothetical M7 class earthquake as the "Western Kanagawa Prefecture Earthquake (WKE)".

In order to detect the pre-, co- and post-seismic deformation of the WKE, the Hot Springs Research Institute of Kanagawa prefecture (HSRI) has carried out continuous monitorings of seismicity and crustal deformation (GPS, EDM, borehole tiltmeters, and groundwater leveling) since 1989. All the data are telemetered to the HSRI in Odawara, and continuous scientific analyses of the data have been made by the HSRI.

Copy right (C) The Society of Geomagnetism and Earth, Planetary and Space Sciences (SGEPSS); The Seismological Society of Japan; The Volcanological Society of Japan; The Geodetic Society of Japan; The Japanese Society for Planetary Sciences.
To apply effectively these three kinds (GPS, EDM and tiltmeters) of the networks for investigating the pre-, co- and post-seismic deformations of the WKE, we need to know their own advantageous characteristics.

Komukai and Ishii (1978) investigated on the detectability of co-seismic deformation by the crustal deformation network of Tohoku University in and around northeast Japan. They found that the detectability of strain components was better than that of tilt components, and that their network could observe strain-steps for earthquakes with magnitudes larger than 7, occurred along the Japan trench. On the other hand, several researchers have studied the detectability of co-seismic deformation by using a hypothesized fault model. Kogita (1985) and Shimazaki (1985) discussed a pattern of temporal change of strain caused by a pre-slip of the Tokai earthquake, based on the data obtained by the Japan Meteorological Agency strain meters. Ishii and Kato (1989) showed the detectability of precursors related with the 1923 Kanto earthquake by using GPS, EDM and strainmeters of Tokyo University. Okada (1993) estimated the anticipated crustal deformations due to the hypothetical WKE fault models proposed by many researchers, and assessed the contribution of each station to detection of a pre-slip for each model.

According to the conventional method similar to a future Tokai earthquake (Kogita, 1985; Shimazaki, 1985) and the 1923 Kanto earthquake (Ishii and Kato,1989), we have to hypothesize the WKE fault model. Unfortunately, although 
many researchers have proposed various kinds of WKE fault models (e.g., Okada, 1993), any reliable models are not yet known at present. Thus, we attempt to assess the detectability for our HSRI network by comparing between the accuracy of each monitoring system (GPS, EDM and tilt meters) and the synthesized co-seismic deformation, which can be estimated from an earthquake magnitude and a hypocentral distance.

\section{The Crustal Deformation Observation Network}

Since 1989, the HSRI has gradually installed 4 Global Positioning System (GPS) receivers, 2 Electric Distance Meter (EDM) networks, 8 borehole-type tiltmeters and 6 groundwater level observations in the western area of Kanagawa prefecture (HSRI, 1999).

Our GPS receivers encircle the other observation sites (EDM, tiltmeter and groundwater level observation sites) in the western Kanagawa prefecture (Fig. 1). Each GPS observation site is equipped with a Trimble 4000SSE GPS receiver and a Geodetic antenna, which is stably fixed on a building or architecture. The stations are operated continuously, record-
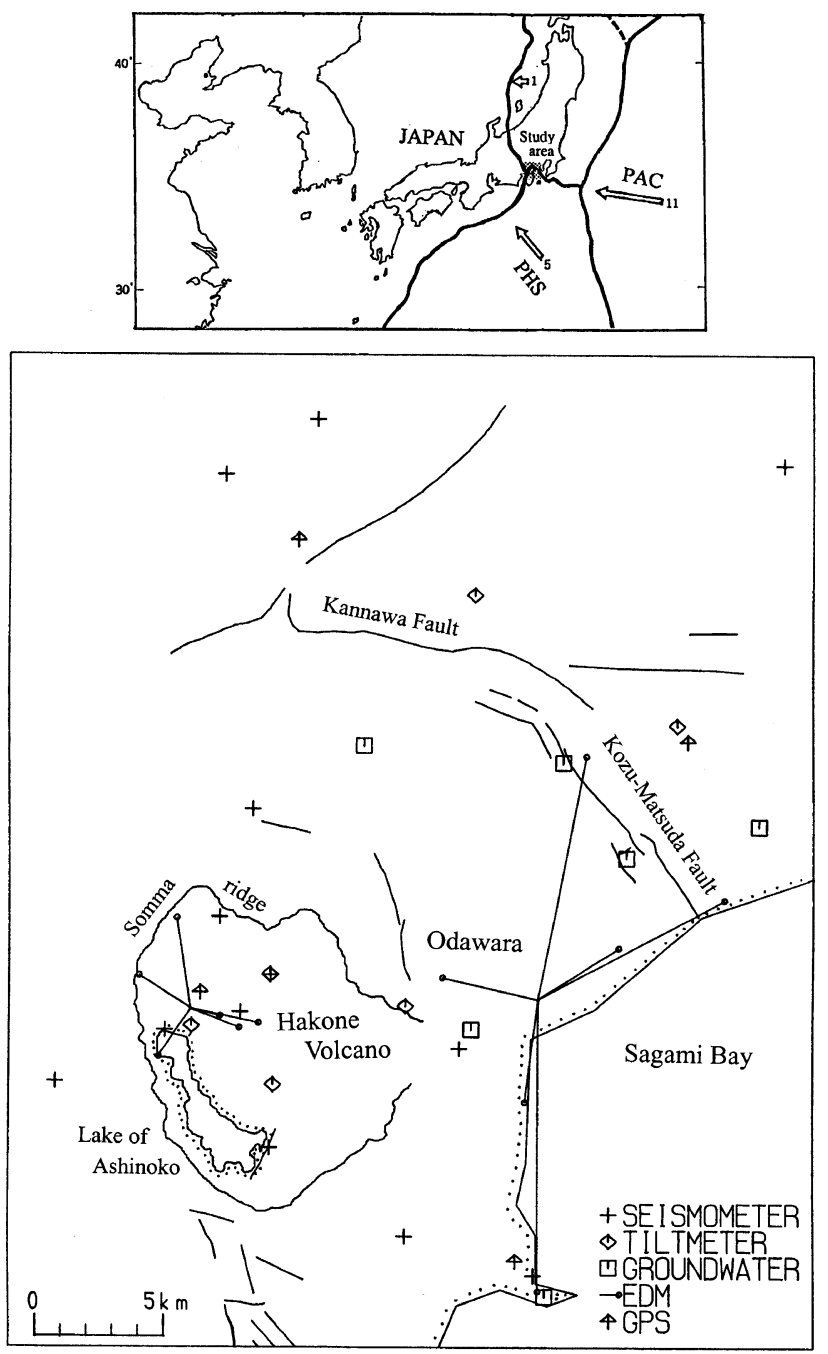

Fig. 1. Station map for continuous monitorings of seismicity and crustal deformation of the Hot Springs Research Institute of Kanagawa prefecture (HSRI). The upper is tectonic map of Japan (PAC, Pacific plate; PHS, Philippine Sea plate). ing GPS observables every 30 seconds. Automated downloads of 6 hours' session data are performed 2 times every day. After download, an automated computer analysis system equipped with the TRIMVEC-PLUS (Ver.E) software processes all the GPS data at the HSRI (Tanada et al., 1995). An average spacing of GPS network is about $20 \mathrm{~km}$. The maximum and minimum baseline lengths are about $29.3 \mathrm{~km}$ and $16.4 \mathrm{~km}$, respectively. The accuracy of observation is $5 \mathrm{~mm}+1 \mathrm{ppm}$ of baseline length for a horizontal distance survey (HSRI, 1999).

2 EDM networks are located in the Odawara and Hakone areas (Fig. 1). Each EDM network has 5 baselines and is equipped with a distance meter WILD DI3000, a thermometer, a hygrometer and a barometer. We use the same system as developed by Tsuneishi (1991). Every prism is stably fixed on bedrock or architecture. Measurements are automatically performed every hour. These data are downloaded every day through the NTT telephone line. The accuracy of observation is $3-5 \mathrm{~mm}+1 \mathrm{ppm}$ of baseline length. The minimum and maximum baselines length of the Odawara EDM network are about $3.8 \mathrm{~km}$ and $11.4 \mathrm{~km}$, respectively The error of measurement is $\pm 7-9 \mathrm{~mm}$ for the minimum baseline and $\pm 14-16 \mathrm{~mm}$ for the maximum baseline. In the Hakone EDM network, the minimum and maximum baseline lengths are about $1.2 \mathrm{~km}$ and $3.6 \mathrm{~km}$, respectively. The error is $\pm 4-6 \mathrm{~mm}$ for the minimum baseline and $\pm 7-9 \mathrm{~mm}$ for the maximum baseline (HSRI, 1999).

8 borehole-type tiltmeters have been installed at the bottoms of about $100 \mathrm{~m}$ depth boreholes in the study area (Fig. 1). Each observation site is equipped with a tiltmeter Akashi JTS-23 (Sato et al., 1980), a thermometer, a rain gauge and a barometer. Measurements are automatically performed every second. The data are transmitted through the NTT D-1 lines to the HSRI on a real-time. The accuracy of observation is 0.01-second degree (Yamaki et al., 1990; HSRI, 1999).

\section{Detectability Analysis}

To estimate the detectability, we apply a simple calculation method, and compare the amount of a co-seismic deformation (displacement and tilt) with the accuracy of observation instrument.

Co-seismic deformation is calculated at observation points

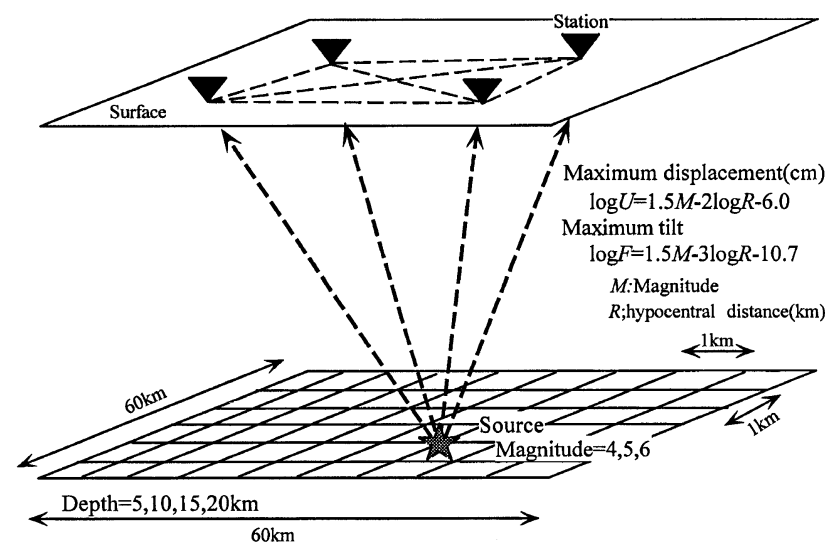

Fig. 2. The model configuration for calculation of co-seismic deformation 

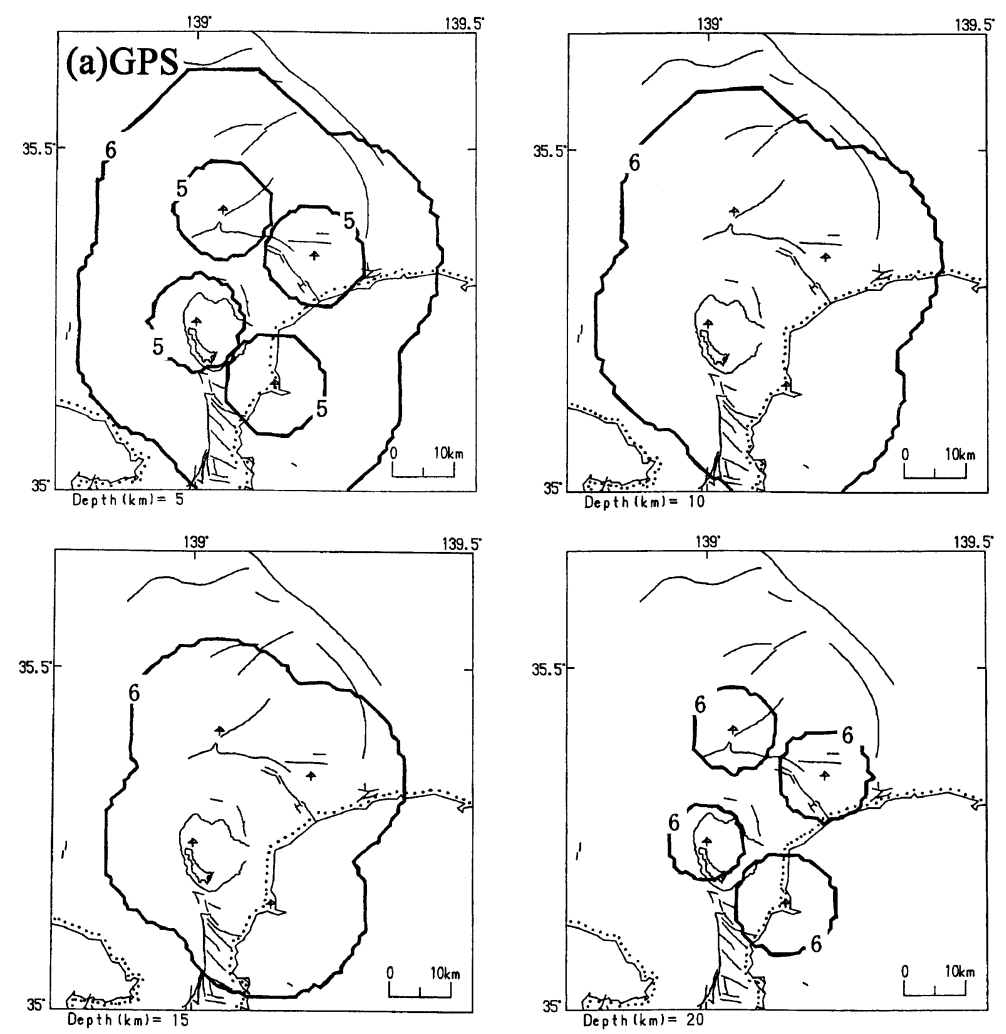

Fig. 3. The contour maps of the detectability for the GPS, EDM and tiltmeter networks. The contour values in the map show earthquake magnitude for detectable the baseline-length change and co-seismic tilt deformation. The focal depths are shown under each frame.

for earthquakes with various magnitudes and hypocentral distances using the method of Okada (1992). He formulated the maximum crustal deformation due to seismic faulting as follows:

$$
\begin{aligned}
& \log U_{\max }=1.5 M-2 \log R-6.0 \\
& \log F_{\max }=1.5 M-3 \log R-10.7,
\end{aligned}
$$

where $U_{\max }$ and $F_{\max }$ are the maximum displacement $(\mathrm{cm})$ and tilt, respectively, $M$ denotes an earthquake magnitude, and $R$ a hypocentral distance. This approach enables us to estimate the maximum value of co-seismic deformation without assuming a focal mechanism.

Figure 2 shows the calculation model in the present study. The maximum co-seismic displacement and tilt caused by each of earthquakes with magnitudes from 4 to 6 and focal depths from 5 to $20 \mathrm{~km}$ are calculated.

The GPS and EDM networks will be able to record a clear change of baseline-length, which is defined here to be a difference between estimates of $U_{\max }$ at two observation points, when the baseline-length change exceeds the threshold value. This critical value is determined from the accuracy of GPS and EDM instruments described in the previous section. The tiltmeter network will be able to record a clear co-seismic tilt deformation, when the maximum co-seismic tilt deformation exceeds the accuracy of tiltmeter instrument.

\section{Results and Conclusions}

Figures 3(a) and (b) show the detectability of the baselinelength change for the GPS and EDM networks. Figure 3(c) shows that of the co-seismic tilt deformation for the tiltmeter network. As a whole, the highest detectability area is located in the central part of our HSRI observation network. The contour values in the map show earthquake magnitude for detectable baseline-length change and co-seismic tilt deformation.

Comparing detectability contour maps for several geodetic networks, we find remarkable results as follows:

(1) For $M=6$ earthquakes, GPS, EDM and tiltmeter networks possibly record the baseline-length change due to earthquakes with focal depths less than $15 \mathrm{~km}$ in the western Kanagawa. The GPS network can widely detect the baseline length change than the EDM network. Moreover, GPS also detects that due to a deeper focus $20 \mathrm{~km}$ earthquake occurring near the stations. These results mean that in the case of calculation model, longer baselines surveyed by GPS are advantageous for the measurement of the baseline-length change than shorter baselines surveyed by EDM.

(2) For $\mathrm{M}=5$ earthquakes, tiltmeters possibly detect the co-seismic tilt deformations due to earthquakes with focal depths less than $10 \mathrm{~km}$ occurring around the network. However, the GPS and EDM networks can detect the baseline length change due to a shallower focus $5 \mathrm{~km}$ earthquake.

(3) Concerning $M=4$ earthquakes, it is difficult for the GPS, EDM and tiltmeter networks to detect the baseline length change and the co-seismic tilt deformation.

The reliable mechanisms of the pre- and post-seismic deformations associated with the WKE are not known at present. Thus, we simply assume that such deformations are roughly in the same order of the co-seismic deformation due 

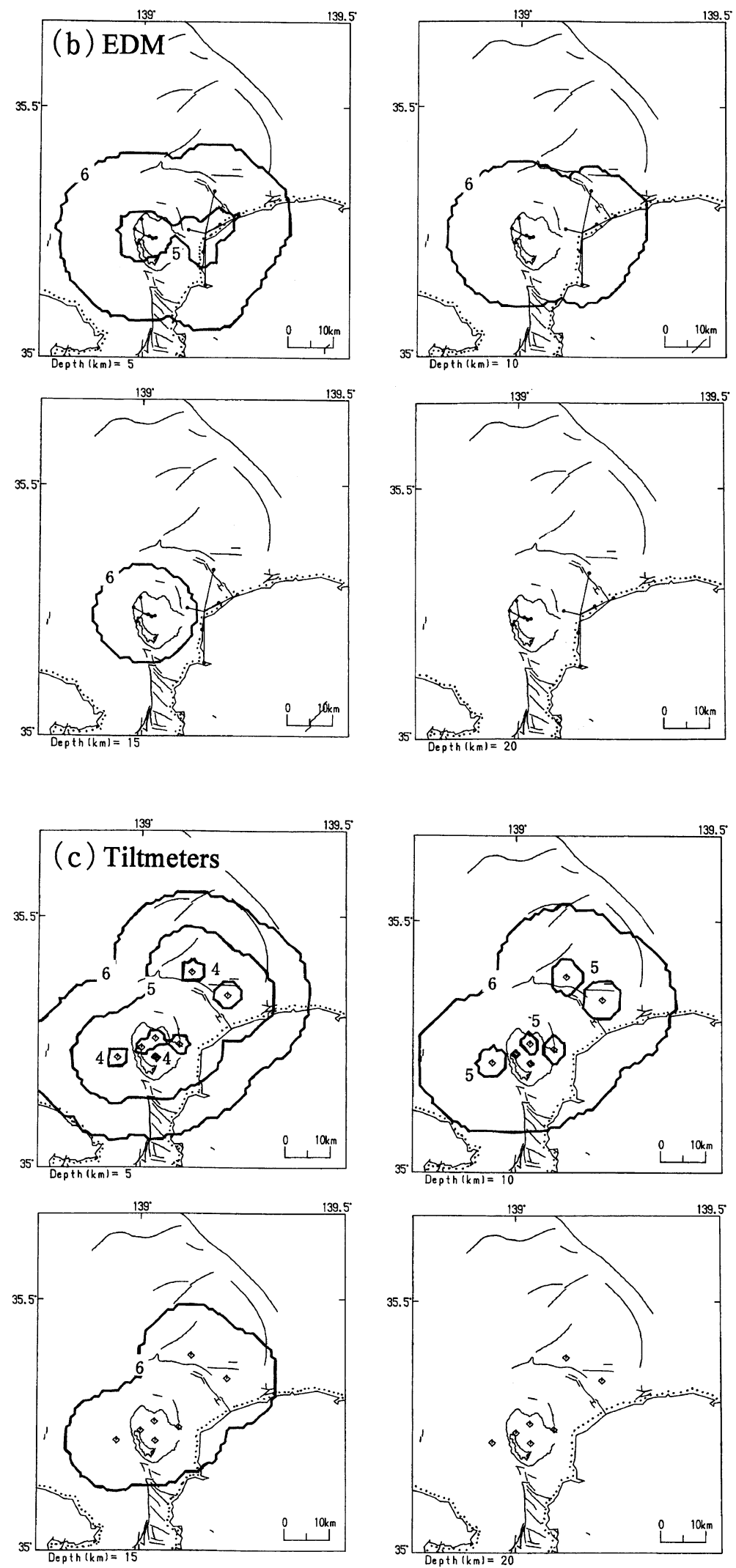

Fig. 3. (continued).

to an earthquake smaller than the M7 class WKE, though plausibility of this assumption should be checked otherwise. On the basis of the above mentioned results of the co-seismic deformation detectability for our HSRI observation network, we can detect the pre- and post-seismic deformations equivalent to that due to the M6 class earthquake with a focal depth shallower than $15 \mathrm{~km}$. We find also that our tiltmeter network can effectively observe deformations of M5 class 
earthquakes with focal depths shallower than $10 \mathrm{~km}$.

The present result shows advantageous characteristics of our HSRI networks and an important constraint on investigating the pre-, co- and post-seismic deformations of the WKE. To better assessment for the monitoring of these deformations, it is necessary to establish the hypothesized WKE fault model and to combine these observations by considering their characteristics.

Acknowledgments. The author would like to thank Prof. S. Iizuka of Tokai Univ. for improvement of the manuscript. I greatly appreciate the useful review by K. Miyashita and S. Shimada. The author is also grateful to the researchers of Hot Springs Research Institute of Kanagawa prefecture for their invaluable advice and helpful discussion.

\section{References}

Hot Springs Research Institute of Kanagawa prefecture, Planning for the "West Kanagawa Earthquake" by the Hot Springs Research Institute of Kanagawa prefecture, Bulletin of the Hot Springs Res. Inst., 29-1/2, 3-40, 1999 (in Japanese).

Ishibashi, K., "Kanagawaken-Seibu-Earthquake" and earthquake prediction 1, Kagaku, 58, 537-547, 1988 (in Japanese).

Ishii, H. and T. Kato, Detectabilities of earthquake precursors using GPS, EDM and Strain meters, with special reference to the 1923 Kanto earthquake, J. Geod. Soc. Japan, 35, 75-83, 1989.

Kogita, S., Investigation of the detection capability of premonitory crustal deformation in the Tokai district, Bull. Earthq. Res. Inst., 60, 461-485,
1985 (in Japanese with English abstract)

Komukai, Y. and H. Ishii, On the detectability of earthquakes and crustal movements in and around the Tohoku district (Northeastern Honshu) (2) Crustal movements, J. Seismol. Soc. Japan, Ser. 2, 31, 445-455, 1978 (in Japanese with English abstract).

Okada, Y., Expected crustal deformation due to seismic faulting, Programme and Abstracts, Seismol. Soc. Japan, 2, 240, 1992 (in Japanese).

Okada, Y., Fault models for hypothetical "West Kanagawa earthquake" and anticipated crustal deformation fields, Journal of Geography, 102(4), 445-456, 1993 (in Japanese).

Sato, H., H. Takahashi, E. Yamamoto, N. Fukuo, M. Uehara, and Y. Terasawa, Development of the crustal tilt observation method using borehole-type tiltmeters, J. Seismol. Soc. Japan, Ser. 2, 29, 93-98, 1980 (in Japanese with English abstract).

Shimazaki, K., Observability of a foreslip on a hypothesized fault of the anticipated Tokai, Japan earthquake, Earthq. Pred. Res., 3, 637-649, 1985

Tanada, T., H. Ito, K. Yamaki, S. Odaka, and T. Hirano, Automatic and continual GPS observation system by Hot Springs Research Institute of Kanagawa Prefecture, Bulletin of the Hot Springs Res. Inst., 26-1, 37-48, 1995 (in Japanese with English abstract).

Tsuneishi, Y., Continuous monitoring of crustal activity in east Izu Peninsula by automatic electronic distance measurement, J. Phys. Earth, 39, 131139, 1991.

Yamaki, K., S. Odaka, H. Ito, T. Tanada, and Y. Oki, Tilt change analyzing system of Hakone volcano, Bulletin of the Hot Springs Res. Inst., 21-3, 17-32, 1990 (in Japanese with English abstract).

T. Tanada (e-mail: tanada@onken.odawara.kanagawa.jp) 